Case Report

\title{
A Case of Adenoid Cystic Carcinoma Mimicking a Bartholin Cyst and Literature Review
}

\author{
Siew Pei Goh $\left(\mathbb{D},{ }^{1}\right.$ Brian McCully, ${ }^{2}$ and Matthew Kyle Wagner ${ }^{3}$ \\ ${ }^{1}$ Ipswich Clinical Unit, University of Queensland, 7 Chelmsford Avenue, Ipswich, QLD 4305, Australia \\ ${ }^{2}$ Obstetrics and Gynaecology, Ipswich General Hospital, 7 Chelmsford Avenue, Ipswich, QLD 4305, Australia \\ ${ }^{3}$ University of Queensland, Brisbane, QLD, Australia
}

Correspondence should be addressed to Siew Pei Goh; siew.goh14@gmail.com

Received 6 December 2017; Accepted 19 February 2018; Published 26 March 2018

Academic Editor: Erich Cosmi

Copyright (C) 2018 Siew Pei Goh et al. This is an open access article distributed under the Creative Commons Attribution License, which permits unrestricted use, distribution, and reproduction in any medium, provided the original work is properly cited.

\begin{abstract}
Adenoid cystic carcinoma of the Bartholin Gland (BG-ACC) is a rare form of vulval cancer with only approximately 350 reported cases since 1864. A review of available literature and case reports suggests an aggressive nature with protracted clinical symptoms and a tendency for local recurrence despite adequate surgical excision with or without adjuvant radiotherapy. Survival rates of $71 \%$ and 59\% are reported at five and ten years. This case report endeavours to add to our body of knowledge regarding this rare disease and thus help broaden and improve our understanding of management and treatment success.
\end{abstract}

\section{Introduction}

We report a case of BG-ACC in Ipswich General Hospital, QLD.

\section{Case Presentation}

A 41-year-old slim female with no previous gynaecological history was seen in the Ipswich Gynaecology Clinic with a 3-month history of a small $2 \mathrm{~cm}$ painless swelling thought to be a left sided Bartholin Gland (BG) cyst. There was no significant past medical history. The patient was booked for elective marsupialisation. At the time of surgery, a solitary solid and mobile mass was noted in the BG, extending into subcutaneous and muscle tissue. An excisional biopsy was performed. Histology identified changes consistent with Adenoid Cystic Carcinoma of the BG involving surgical margins with perineural invasion. The tumour showed extensive cribriform and tubular islands of malignant epithelium infiltrating hyaline stroma, containing intraluminal basement membrane like material. It also stained positive with Calponin and p53, markers which are also found in adenoid cystic carcinoma of the salivary gland. A staging $\mathrm{CT}$ of the chest, abdomen, and pelvis revealed no evidence of metastasis. Patient underwent radical local incision and bilateral inguinal lymph node dissection and was diagnosed with FIGO Stage 1b Vulval cancer. She completed six cycles of adjuvant radiotherapy, $63 \mathrm{~Gy} / 33$ fractions to her vulva using VMAT (Vaginal Sparing with Volumetric Modulated Arc Therapy), and has remained disease-free at 9 months with preservation of sexual function.

\section{Discussion}

Adenoid cystic carcinoma (ACC) of the Bartholin Gland (BG) is a rare form of vulval cancer with only approximately 350 reported cases since Klob in 1864 [1].

ACC constitutes $15-25 \%$ of all Bartholin Gland cancers.

The average age of diagnosis is 49 years with range between 25 and 80 years [2].

To date, little is known regarding the natural history of ACC of BG. It most often presents without antecedent history of benign disease. Once diagnosed, its behaviour is often described as biologically aggressive and unpredictable. Its clinical course is often protracted and there is a tendency for perineural invasion and local recurrence [2, 3]. Felix et al. 1993 suggested that Human papillomavirus may play a pathogenic role [4]. Copeland et al. 1986 identified a possible 
link with pregnancy, noting that 7 of 14 of their patients were pregnant at the time of diagnosis. In one patient, growth of the tumour was rapid suggesting hormonal sensitivity [3].

BG-ACC can present as a vulval mass, with or without symptoms such as pain, ulceration, pruritus, abnormal bleeding, or dyspareunia. It may also present as palpable solid, cystic, or abscessed area within a Bartholin cyst. The mass rarely occurs bilaterally. Clinicians should have heightened suspicion for malignancy when there is palpable solid mass within the cyst, underlying fixation to surrounding tissues, and/or cyst or abscess that does not respond or worsens despite treatment [5]. Due to its tendency to infiltrate perineural spaces, patients may experience itching and burning before a mass becomes palpable [6].

ACC is a histological diagnosis. Bartholin Gland ACC is histologically similar to ACC of the salivary gland, upper respiratory tract (lacrimal, nasopharynx), and breast. There are 3 histological types of ACC, that is, cribriform, tubular, and solid. Of these, the tubular form tends to be best differentiated and confers the most favourable prognosis. On the other hand, solid form is associated with highest incidence of metastasis and significantly lower survival rate $[7,8]$.

Microscopic examination of BG-ACC typically demonstrates cribriform pattern consisting of nests and columns of cells arranged concentrically around gland-like spaces filled with eosinophilic Periodic Acid-Schiff- (PAS-) Positive material [9-12]. Immunohistochemical staining may reveal low-molecular-weight keratins, carcinoembryonic antigen, lysozyme, alpha-antichymotrypsin, S100, and type IV collagen [11]. Ramanah et al. took a step further by performing specific antibody stains of brain metastases from BG-ACC, which revealed positive cytokeratin (CK) AE1/AE3, CK7, and epithelial membrane antigen (EMA); weakly positive S100 and progesterone receptor; and negative CK20 and estrogen receptor [10].

Initial treatment of Bartholin Gland Cancer is similar as that for vulval cancer. Literature review supports wide local excision, with or without inguinal lymphadenectomy $[13,14]$. Post-op adjuvant radiotherapy is generally recommended when there is a positive surgical margin, deep local and perineural invasion, and local recurrence $[15,16]$. Data is lacking for the role of chemotherapy and biological treatment of BG-ACC. Few studies have trialled 5-fluorouracil, adriamycin, cyclophosphamide, cisplatin, CPT-11 (Irinotecan), methotrexate, and doxorubicin with varying efficacy [17-20]. A single patient trial of adjuvant Tamoxifen on metastatic BG-ACC delayed disease progression for 4 years while maintaining quality of life [21].

Prognosis for BG-ACC is similar to a low grade vulval cancer. Survival was quoted by Lelle et al. 1994 to exceed $71 \%$ and $59 \%$ at five and ten years [2, 19]; while disease-free rates were reported to be $47-83 \%$ and $33-38 \%$, respectively [11]. The longest reported survival is 31 years [2].

Surgical resection margin appears to be the single most important factor for cure [22]. Groin nodal status on the other hand is thought to be the main determinant of survival [23]. Routine lymphadenectomy however does not appear to improve survival and prognosis [20]. Postoperative adjuvant radiotherapy is thought to be effective in reducing recurrence rate for positive surgical margins and deep local and perineural invasion [18].

Sadly, local recurrence and metastasis can occur long after primary treatment [24]. Bones and lungs are the most common site of metastasis; other sites reported are liver, kidney, and brain [25]. Late recurrences and metastases are associated with poor prognosis $[9,10]$.

More research and case reports on this rare cancer are needed in order to further comprehend and manage the disease. The role of chemotherapy and biological treatment with hormones or receptor antibody has potential for controlling local recurrence and metastatic disease of adenoid cystic carcinoma of the vulva and their role should be further explored.

The purpose of this report is to remind the clinical practitioner that Adenoid cystic carcinoma (ACC) of the Bartholin Gland (BG) can occur. The authors acknowledge its rarity but suggest that a differential diagnosis which includes a suspicion of its role in the aetiology of Bartholin Gland disorders may well help the optimization of appropriate patient care.

\section{Consent}

Verbal and written consent have been obtained from patient for publishing the case in an open access journal.

\section{Conflicts of Interest}

The authors declare that there are no conflicts of interest regarding the publication of this article.

\section{Acknowledgments}

The authors thank Dr. Kasturi Vaska, Pathologist in Princess Alexandra Hospital, for provision of histology photos.

\section{Supplementary Materials}

(1) Contrast CT showing an irregular area on the left perineum consistent with recent biopsy. (2) $\mathrm{H} \& \mathrm{E}$ stain of the tumour showing (A) perineural invasion and (B) cribriform-tubular arrangement of tumour cells around acellular spaces and pseudomucinous basement membrane. (Supplementary Materials)

\section{References}

[1] T.-L. C. Hwang, Y.-C. Hung, and H.-W. Chang, "Adenoid cystic carcinoma of Bartholin's gland," Taiwanese Journal of Obstetrics and Gynecology, vol. 51, no. 1, pp. 119-120, 2012.

[2] R. J. Lelle, K. P. Davis, and J. A. Roberts, "Adenoid cystic carcinoma of the Bartholin's gland: the University of Michigan experience," International Journal of Gynecological Cancer, vol. 4, no. 3, pp. 145-149, 1994.

[3] L. J. Copeland, N. Sneige, D. M. Gershenson, P. B. Saul, C. A. Stringer, and J. C. Seski, "Adenoid cystic carcinoma of Bartholin 
gland," Obstetrics and Gynaecology, vol. 67, no. 1, pp. 115-120, 1986.

[4] J. C. Felix, R. J. Cote, E. E. W. Kramer, P. Saigo, and G. H. Goldman, "Carcinomas of Bartholin's gland: histogenesis and the etiological role of human papillomavirus," The American Journal of Pathology, vol. 142, no. 3, pp. 925-933, 1993.

[5] F.-Y. Hung, K.-L. Wang, and T.-Y. Wang, "Adenoid cystic carcinoma of Bartholin's gland: A case report," Taiwanese Journal of Obstetrics and Gynecology, vol. 44, no. 1, pp. 72-74, 2005.

[6] S. E. Depasquale, T. B. Mcguinness, C. E. Mangan, M. Husson, and M. B. Woodland, "Adenoid cystic carcinoma of Bartholin's gland: A review of the literature and report of a patient," Gynecologic Oncology, vol. 61, no. 1, pp. 122-125, 1996.

[7] T. Yamada, S. Yanagawa, H. Iwai, T. Ishigaki, A. Nawa, and F. Kikkawa, "High-dose-rate interstitial brachytherapy of Bartholin's gland: A case report," Gynecologic Oncology, vol. 77, no. 1, pp. 193-196, 2000.

[8] K. H. Perzin, P. Gullane, and A. C. Clairmont, "Adenoid cystic carcinomas arising in salivary glands. A correlation of histologic features and clinical course," Cancer, vol. 42, no. 1, pp. 265-282, 1978.

[9] M. A. Hatiboglu, M. Cosar, A. C. Iplikcioglu, and D. Ozcan, "Brain metastasis from an adenoid cystic carcinoma of the Bartholin gland," Journal of Neurosurgery, vol. 102, no. 3, pp. 543-546, 2005.

[10] R. Ramanah, E. Allam-Ndoul, C. Baeza, and D. Riethmuller, "Brain and lung metastasis of Bartholin's gland adenoid cystic carcinoma: a case report," Journal of Medical Case Reports, vol. 7, article 208, 2013.

[11] F. M. Woida and A. Ribeiro-Silva, "Adenoid cystic carcinoma of the Bartholin gland: an overview," Archives of Pathology and Laboratory Medicine, vol. 131, no. 5, pp. 796-798, 2007.

[12] S. Yamagiwa, K. Niwa, Y. Yokoyama et al., "Primary adenoid cystic carcinoma of Bartholin's gland: A case report," Acta Cytologica, vol. 38, no. 1, pp. 79-82, 1994.

[13] J. S. Berek and A. Karam, Vulvar Cancer: Epidemiology, Diagnosis, Histopathology, and Treatment of Rare Histologies, UpToDate, 2017.

[14] R. Kumar, M. Singhal, R. Acharya, S. Kudesia, and N. Chawla, "Adenoid cystic carcinoma of Bartholin's gland-a rare entity likely to be misdiagnosed," Revista Espanola de Patologia, vol. 44, no. 4, pp. 213-215, 2011.

[15] L. Agolli, M. F. Osti, V. Armosini, V. De Sanctis, M. Valeriani, and R. M. Enrici, "Adenoid cystic carcinoma of Bartholin's gland receiving adjuvant radiation therapy: case report," European Journal of Gynaecological Oncology, vol. 34, no. 5, pp. 487-488, 2013.

[16] M. Nowak, M. Rycel, M. Szpakowski, A. Kulig, J. Sobotkowski, and A. Dziki, "Interdisciplinary treatment of the patient with adenoid cystic carcinoma of the Bartholin's gland resulting in 15 years' survival: A case report and review of literature," Przeglad Menopauzalny, vol. 13, no. 5, pp. 310-312, 2014.

[17] F. S. Abrao, A. F. Marques, F. Marziona, M. S. Abrao, L. C. U. Junqueira, and H. Torloni, "Adenoid cystic carcinoma of bartholin's gland: Review of the literature and report of two cases," Journal of Surgical Oncology, vol. 30, no. 2, pp. 132-137, 1985.

[18] C. Alsan, V. Vinh-Hung, F. Eren et al., "Adenoid cystic carcinoma of the Bartholin's gland: case report and systematic review of the literature," European Journal of Gynaecological Oncology, vol. 32, no. 5, pp. 567-572, 2011.
[19] E. Takatori, T. Shoji, J. Miura, S. Takeuchi, and T. Sugiyama, "Chemoradiotherapy with irinotecan (CPT-11) for adenoid cystic carcinoma of Bartholin's gland: a case report and review of the literature," Gynecologic Oncology Reports, vol. 4, pp. 16-19, 2013.

[20] G. Yoon, H. S. Kim, Y. Y. Lee et al., "Analysis of clinical outcomes of patients with adenoid cystic carcinoma of Bartholin's glands," International Journal of Clinical and Experimental Pathology, vol. 8, no. 5, pp. 5688-5694, 2015.

[21] S. Hsu, R. Wang, C. Lu et al., "Report of two cases of adenoid cystic carcinoma of Bartholin's gland and review of literature," Taiwanese Journal of Obstetrics and Gynecology, vol. 52, no. 1, pp. 113-116, 2013.

[22] M. Momeni, Y. Korotkaya, G. Carrasco, and M. Prasad-Hayes, "Adenoid cystic carcinoma of Bartholin's gland: case report," Acta Medica Iranica, vol. 54, no. 12, pp. 820-822, 2016.

[23] R. S. Leuchter, N. F. Hacker, R. L. Voet, J. S. Berek, D. E. Townsend, and L. D. Lagasse, "Primary carcinoma of the bartholin gland: a report of 14 cases and review of the literature," Obstetrics \& Gynecology, vol. 60, no. 3, pp. 361-368, 1982.

[24] S.-Y. V. Yang, J.-W. Lee, W.-S. Kim et al., "Adenoid cystic carcinoma of the Bartholin's gland: Report of two cases and review of the literature," Gynecologic Oncology, vol. 100, no. 2, pp. 422-425, 2006.

[25] S. Milchgrub, E. L. Wiley, F. Vuitch, and J. Albores-Saavedra, "The tubular variant of adenoid cystic carcinoma of the Bartholin's gland," American Journal of Clinical Pathology, vol. 101, no. 2, pp. 204-208, 1994. 


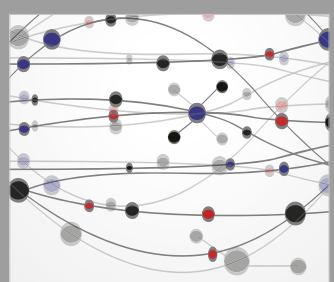

The Scientific World Journal
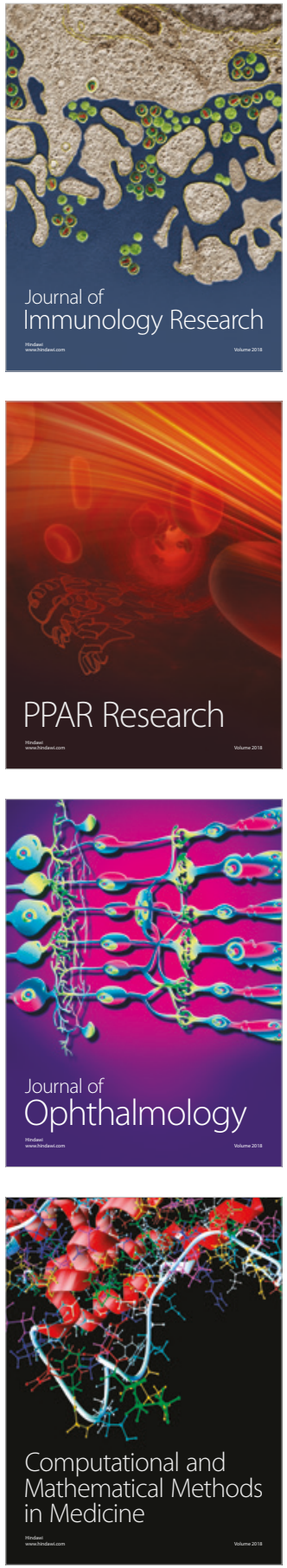

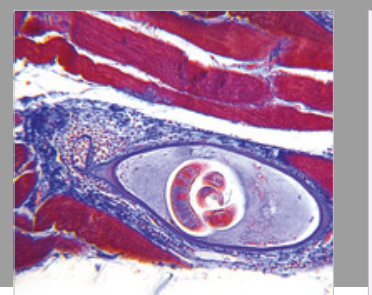

Gastroenterology Research and Practice

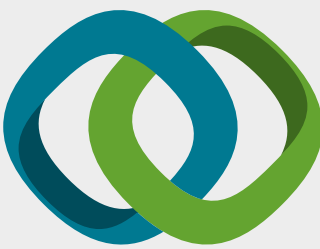

\section{Hindawi}

Submit your manuscripts at

www.hindawi.com
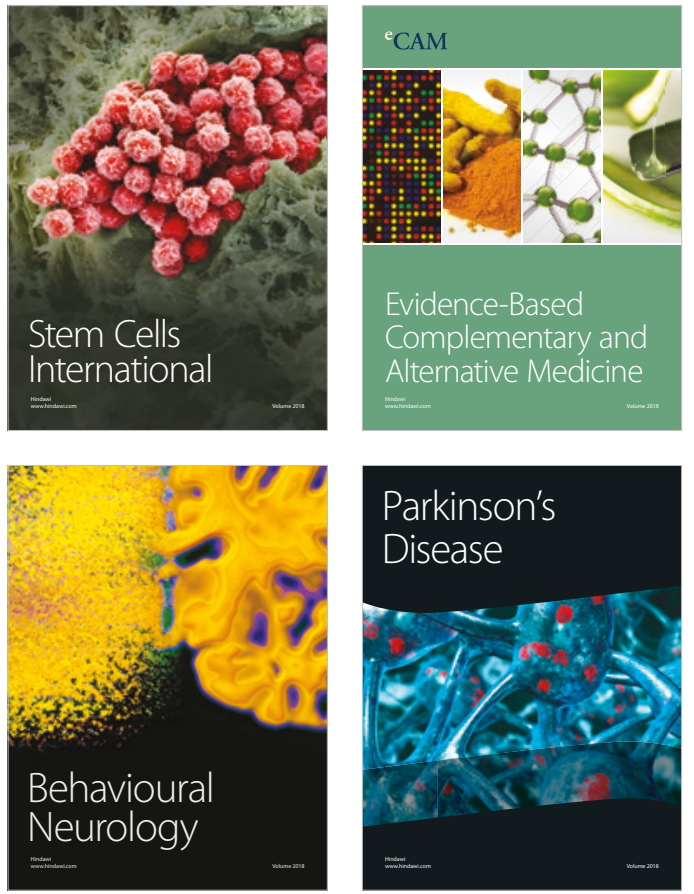

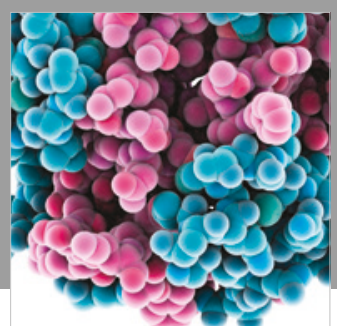

ournal of

Diabetes Research

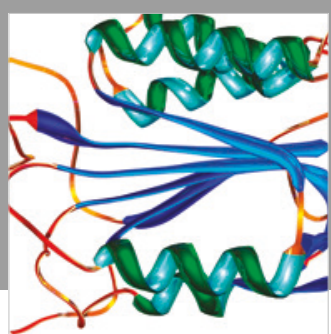

Disease Markers
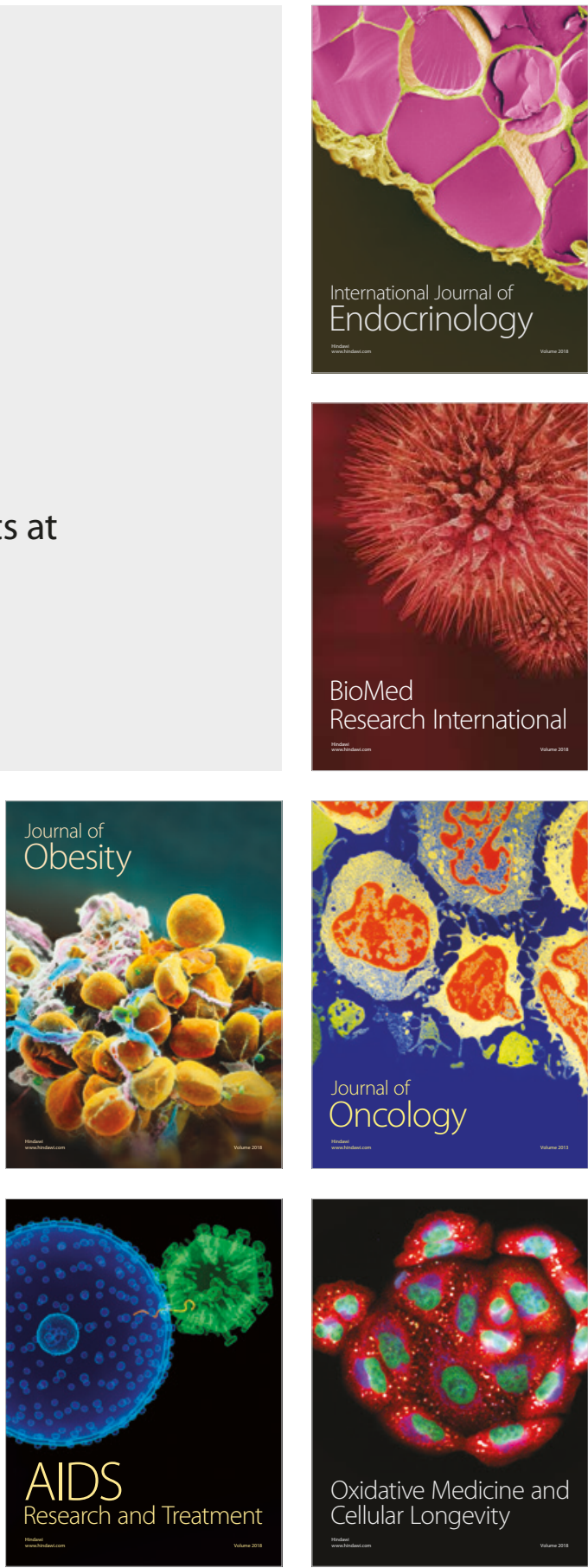